cubical. It can be shown that the ratio of surface to projected area for a rectangular parallelopiped in random motion is $18 \pi /(8+\pi)$ independent of the relative lengths of the axes, that is, whether the particle is flat, cubical or elongated. If this factor is used to compute the specific surface of calcined and hydrated alumina from the values of $A_{0}\left(=2 A_{G}\right)$ found by graphical extrapolation, very good agreement over a wide range of samples is obtained with other estimates of the specific surface from airpermeability, sedimentation, and microscope data, if allowance is made for the flat shape of the calcined alumina crystals in the last two instances.

It thus appears that this method, which is rapid and economical of sample material, is capable of giving a good estimate of the specific surface of alumina powders over a wide range of values $(1,000-$ $\left.40,000 \mathrm{~cm}^{2} / \mathrm{gm}.\right)$, and may find application to other transparent crystalline materials. The extrapolation method of evaluating $A_{0}$ seems to overcome the difficulty due to unknown variations in opacity factor with particle size.

If the Hilger Spekker absorptiometer, having a relatively large angle of acceptance, is employed for the measurement, the value of the specific surface has been found to be approximately $4 A_{0}$, instead of $2 \cdot 55 A_{0}$. This result is no doubt fortuitous, and may be ascribed to the fact that some of the light refracted or scattered out of the parallel beam by the particles is still capable of striking the sensitive surface of the photocell, thereby reducing the estimate of $A_{0}$.

It is hoped to publish a more detailed account of this work at a later date.

Research Laboratories,

B. A. Sсотт

British Aluminium Co., Ltd., Chalfont Park,

Gerrards Cross, Bucks.

'J. Opt. Soc. Amer., 37, (6), 475 (1947).

\section{Luminescence Efficiency Changes in Zinc Sulphide Phosphors Below Room Temperature}

AT temperatures below those at which thermal quenching of huminescence occurs in zinc sulphide phosphors (as shown by the higher temperature forms of the curves of Fig. 1), there is often a slow temperature variation of the luminescence efficiency. 'The sign of the temperature coefficient of this variation may be positive or negative, being dependent on the wavelength of the exciting radiation. Typical efficiency

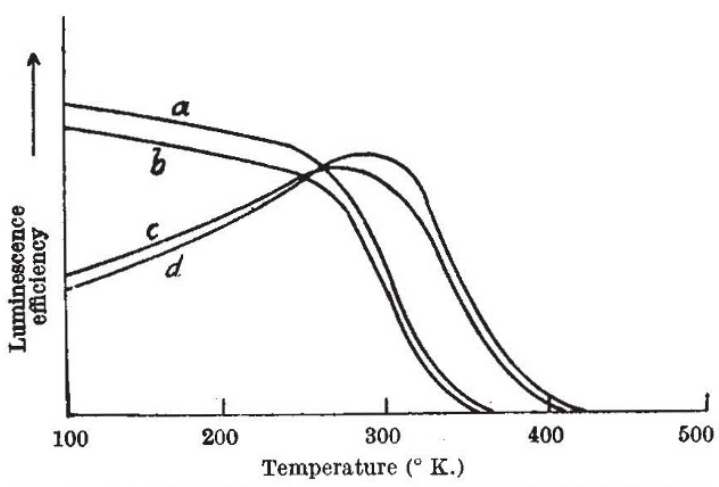

Fig. 1. LUMINESCENCE EFFICIENCY v8. TEMPERATURE VARIATION BOR ZNS-ZN PHOSPHOR. $\lambda_{\text {exc }}$ FOR THE FOUR CURVES ARE (a) 2537 A.; (b) 3132 A.; (c) 3653 A. ; (d) 4043 A.

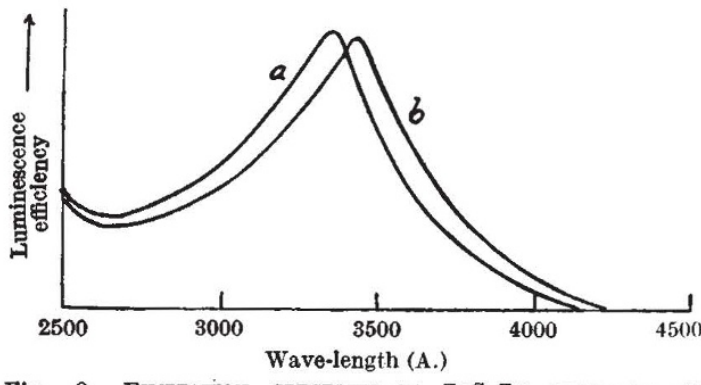

Fig. 2. EXOITATION SPEOTRUM OF ZNS-ZN PHOSPHOR AT (a) $90^{\circ} \mathrm{K} .,(b) 230^{\circ} \mathbf{K}$.

temperature curves for a self-activated zinc sulphide phosphor are given in Fig. 1 for different excita tion wave-lengths. This behaviour has been previously observed by Schön ${ }^{1}$, and recently Williams and Eyring ${ }^{2}$ have attempted to explain it in terms of the intrinsic luminescence centre configurations. Their treatment gives a slow rise in efficiency with temperature, of an exponential form for longer wave. length excitation; but it cannot explain the fall in efficiency with temperature at shorter wave-lengths.

We have made measurements of the excitation spectra, that is, the variation of efficiency of luminescence excitation with wave-length of the exciting radiation, of various specimens of zinc sulphide phosphors. In particular, studies of the change in these spectra with temperature have been made. Spectra measured at two different temperatures for a typical self-activated zine sulphide phosphor are shown in Fig. 2. By comparison of the curves of Figs. 1 and 2, it is found that the temperature shift of the excitation spectra (Fig. 2) can account for the slow rise or fall of luminescence efficiency over the same temperature range at various wave-lengths (Fig. 1). We have measured the temperature shift in $\mathrm{A} .1^{\circ} \mathrm{K}$. of the excitation spectra of typical phosphors and find that it is the same as the temperature coefficient for the absorption edge shift in these phosphor types as measured by Gisolf ${ }^{3}$. A theoretical study due to Möglich and Rompe ${ }^{4}$ has shown that the absorption edge shift with temperature agrees with that expected from the known thermal expansion of the phosphor crystal lattice.

The accompanying table gives a comparison of values for temperature coefficients of the absorption edge shift measured by Gisolf, and the shift of the excitation spectra from our measurements between $90^{\circ} \mathrm{K}$. and $290^{\circ} \mathrm{K}$.

\begin{tabular}{lc} 
Phosphor & $\begin{array}{c}\text { Absorption edge shift } \\
\text { (Gisolf) }\end{array}$ \\
ZnS-Cu & $0.425 \mathrm{~A} \cdot .^{\circ} \mathrm{K}$. \\
ZnS-Ag & $0.45 \mathrm{~A} .1^{\circ} \mathrm{K}$. \\
ZnS-Zn & \multicolumn{2}{c}{}
\end{tabular}
Temperature coefifients. Excitation spectrum shift (our measurements) $0.5 \pm 0.05 \mathrm{~A} . /^{\circ} \mathrm{K}$. 0.5 圭 $0.05 \mathrm{~A} .1^{\circ} \mathrm{K}$.

It is concluded from the above experimental studies that the thermal expansion of the phosphor crystal lattice and its effect on the impurity centres responsible for emission, which are dispersed in the lattice, can cause the above efficiency versus tempera. ture variations and their changes with wave-length of exciting radiation.

\section{G. F. J. GaRLIOK}

A. F. Gibson

Physics Department,

University, Birmingham, 15. Nov. 24.

2 Schön, M., Naturwiss., 31, 169 (1943).

Williams, F. E., and Eyring, H., J. Chem. Phys., 15, 289 (1947),

' Gisolf, J. H., unpublished work (1938) quoted in ref. 4.

- Moglich, F., and Rompe, R., Z. Phys., 119, 472 (1942). 